\title{
CONTROVÉRSIAS E PRODUÇÃO DO CONHECIMENTO SOBRE MOVIMENTOS SOCIAIS DO CAMPO NO BRASIL*
}

\author{
CONTROVERSIES AND THE PRODUCTION OF KNOWLEDGE \\ ABOUT AGRARIAN SOCIAL MOVEMENTS IN BRAZIL
}

\author{
Joaquim Pinho Pinheiro ${ }^{1}$
}

\begin{abstract}
RESUMO
Este trabalho aborda controvérsias como situações importantes para a compreensão da produção e circulação do conhecimento científico. O objetivo é analisar como fatores extra científicos se relacionam à validação e à circulação de argumentos resultantes do debate em uma comunidade acadêmica, por meio do estudo de controvérsias. As controvérsias analisadas dizem respeito ao lugar da reforma agrária e dos movimentos sociais do campo na agenda política brasileira. O objeto estudo são três controvérsias, quais sejam, anomia, partidarização dos movimentos sociais do campo e a relação entre engajamento social e político de pesquisadoras e pesquisadores com a produção do conhecimento científico. As controvérsias aqui analisadas são desdobramentos de disputas em torno das análises do sociólogo José de Souza Martins. A reconstrução de controvérsias foi realizada a partir da identificação de temas geradores, de diferentes participantes que convergiram ou divergiram em posições e argumentos e do desenvolvimento do debate. O corpus de pesquisa foi constituído de artigos científicos, capítulos de livros, artigos de jornais e revista de grande circulação que publicizaram as controvérsias. O estudo aponta que, por meio do estudo de controvérsias, é possível compreender que a atividade científica pode ser afetada por fatores sociais e que os pressupostos de imparcialidade e objetividade podem perder força explicativa diante de mediações sociais na produção e circulação do conhecimento científico.
\end{abstract}

Palavras-chaves: Produção e circulação do conhecimento. Controvérsias. Movimentos sociais.

\begin{abstract}
This work addresses controversies as important situations for understanding the production and circulation of scientific knowledge. The objective is to analyze how extra scientific factors are related to the validation and circulation of arguments resulting from the debate in an academic community, through the study of controversies. The controversies analyzed concern agrarian reform and social movements in the countryside on the Brazilian political agenda. Three controversies are analyzed, namely, anomie, the partisanship of social movements and the relationship between the engagement of researchers with the production of scientific knowledge. These controversies are the result of disputes around the analysis of sociologist José de Souza Martins. The work was carried out by reconstructing controversies from the
\end{abstract}

\footnotetext{
* $\mathrm{O}$ autor agradece às revisoras e aos revisores pelos comentários que colaboraram anonimamente com este artigo por meio do diálogo entre pessoas que não sabe quem são e com os quais não houve comunicação direta.

${ }^{1}$ Doutor em Sociologia - UnB. Professor voluntário - UnB. e-mail: joaquim_pinheiro@ yahoo.com.br
} 
identification of generating themes, from different participants who converged or diverged in positions and arguments and from the development of the debate. The research corpus consisted of scientific articles, book chapters, newspaper articles and a widely circulated magazine that publicized the controversies. The study points out that, through analyses of controversies, it is possible to understand that scientific activity can be affected by social factors and that the assumptions of impartiality and objectivity can lose explanatory force in the face of social mediations in the production and circulation of scientific knowledge.

Keywords: Production and circulation of knowledge. Controversies. Social Movements.

\section{INTRODUÇÃO}

Este artigo investiga as relações entre sociedade e conhecimento científico por meio de controvérsias. Trata-se de uma agenda de pesquisa que cresceu no Brasil nas últimas décadas, embora em outras partes do mundo isso ocorra há mais tempo. O trabalho aborda as controvérsias científicas para analisar como o conhecimento é produzido a partir da relação de pesquisadoras e pesquisadores com os contextos sociais e políticos, por meio do debate sobre anomia e partidarização dos movimentos sociais do campo e a relação entre engajamento social e político de pesquisadoras e pesquisadores com a produção do conhecimento científico, iniciado por José de Souza Martins. O autor apresentou análises que desencadearam as controvérsias por meio de argumentos e contra-argumentação.

Busca-se responder à seguinte pergunta: como os contextos sociais interferem nas diferentes interpretações de pesquisadoras e pesquisadores por meio das controvérsias científicas? O objetivo é analisar como controvérsias científicas são permeadas por fatores extra científicos ${ }^{2}$ que influenciam a validação, a aceitação e o uso dos resultados de pesquisas pela comunidade acadêmica. Os fatores extra científicos relacionam-se a fatos e a situações sociais, políticas e econômicas que se interpenetram com a atividade científica.

\footnotetext{
${ }^{2}$ Um exemplo desse processo foi o projeto Camelot, em 1963, idealizado pelo departamento de defesa dos Estados Unidos em parceria com a American University. O objetivo do projeto foi descobrir as causas de revoltas e revoluções em países em desenvolvimento, especialmente na América Latina, e propor ações aos governos locais para amenizar as condições que que deram origem aos conflitos internos. Outro exemplo, que ocorreu em 2015, foi a invasão de cultivos experimentais de plantas transgênicas da empresa Suzano Papel e Celulose por cerca de mil mulheres do MST. O objetivo da ação foi influenciar a decisão da Comissão Técnica Nacional de Biossegurança (CTNBio) sobre a liberação de plantio comercial de eucalipto geneticamente modificado.
} 


\section{Revista \\ Debates Insubmissos}

O estudo de controvérsias é relevante para compreender a produção social do conhecimento acadêmico, pela importância do debate sobre o problema agrário no Brasil e pela atuação dos movimentos sociais do campo na sociedade e na política brasileiras. Outro aspecto relevante do trabalho é o caráter inovador do estudo das controvérsias na análise da produção científica sobre os processos sociais do campo, até agora pouco significativo.

Utiliza-se o recorte de controvérsias sobre movimentos sociais do campo, iniciadas por José de Souza Martins e que envolveram diversos pesquisadores e pesquisadoras. O artigo identifica os temas geradores das controvérsias e os participantes do debate, além de analisar o contexto social em que ocorreram. O corpus de pesquisa foi constituído por artigos científicos, capítulos de livros, tese e dissertações que registraram partes do debate, além de artigos dos jornais Folha de S. Paulo e O Estado de São Paulo e da revista Caros Amigos. Esses veículos foram selecionados por serem meios de publicização das controvérsias para o grande público. $\mathrm{O}$ recorte dos temas possibilitou a identificação de participantes do debate. Eles foram, posteriormente, agrupados como membros do core set, o grupo de pesquisadoras e pesquisadores que participam das controvérsias. A análise dos dados foi realizada a partir da identificação de participantes e das posições assumidas por eles no debate, bem como pelos argumentos e contraargumentos por eles utilizados. Além disso, relacionou-se os momentos das controvérsias aos cenários sócio-políticos em que ocorrem de modo a permitir a compreensão da a influência dos fatores extra científicos na produção do conhecimento acadêmico.

A primeira parte do artigo faz uma contextualização da importância das controvérsias na ciência em construção. A segunda parte aborda as controvérsias na produção e circulação do conhecimento científico como disputas de posições e de argumentos. A terceira parte caracteriza as controvérsias sobre movimentos sociais do campo e seu core set. A quarta parte reconstrói as controvérsias, a partir do corpus de pesquisa. A quinta parte analisa como o contexto social e político influenciou a construção do conhecimento científico sobre os movimentos sociais do campo. A última parte apresenta as considerações finais. 


\section{A CONTROVÉRSIA NA CIÊNCIA EM CONSTRUÇÃO}

O conhecimento científico é regularmente produzido e reproduzido a partir de determinadas estratégias_comuns de pesquisa que são baseadas no uso de teorias, métodos, técnicas ou instrumentos. Este é o caminho seguro trilhado por pesquisadoras e pesquisadores para que suas análises e argumentos alcancem o reconhecimento na comunidade acadêmica e na sociedade. O produto desses processos é o que KUHN (1998) define como ciência normal. O autor aponta que, nesse modo de produção do conhecimento, a pesquisadora ou pesquisador devem "obedecer a regras que limitam tanto a natureza das soluções aceitáveis como os passos necessários para obtê-las" (KUHN, 1998, p. 61). Além disso, deve existir uma rede de compromissos ou adesões, por meio de conceitos, teorias, metodologias e instrumentos, que relaciona ciência normal à resolução de um quebra-cabeças, no qual as regras que governam a montagem são a utilização das peças disponíveis e entrelaçá-las de tal modo que não fiquem espaços vazios entre elas (KUHN, 1998).

Por esse caminho, a maioria de cientistas volta-se para a produção de convergências com seus pares para alcançar consensos. Essa confluência se apoia em uma base lógica que sustenta a argumentação e a comprovação de pesquisas pela saturação de dados ou experimentos comprobatórios, pela reprodução de um modo de coleta e análise de dados em uma pesquisa de campo (VALÉRIO e PINHEIRO, 2008) e pelo uso de quadros teóricos validados e reconhecidos como cânone pelo mainstream. Fazer ciência, nessa perspectiva, conduz a um pensar e agir repetitivos, segundo uma sequência de etapas, e a uma reprodução de rotinas (COLLINS, 2011).

Um dos problemas da busca por essa ordenação da construção do conhecimento é que o modo de fazer ciência, aprendido no passado e reproduzido no presente, restringe ou elimina a identificação e a interpretação de novas situações. A adesão a um modo de produção do conhecimento já consolidado reduz ou elimina a percepção de novas situações e a produção de novas interpretações sobre fatos e realidades conhecidas ou a descobrir (COLLINS, 2011).

Por outro lado, as situações em que os estudos ainda não alcançaram consenso são "momentos do processo de produção do conhecimento nos quais os resultados ainda estão em debate, pois as evidências empíricas permitem várias interpretações” (MATTEDI, 2006, p. 174). 
Podem ocorrer disputas de posições e argumentos e tornar-se polêmicas quando chamam a atenção da comunidade científica, que é provocada a questionar ou recusar argumentos e posições. Nesses casos, se estabelece uma controvérsia.

Cientistas sociais e historiadores, há muito tempo, estudam disputas expressas em controvérsias. O objetivo é compreender os vários papeis e posições que as partes envolvidas assumem, o engajamento e o desengajamento, o contexto em que se situam os grupos em disputa, a expansão para o domínio público, o encerramento ou persistência do debate ao longo do tempo e a construção social da reivindicação do status de ciência durante as disputas (MARTIN e RICHARDS, 1995). Assim, é no ambiente das controvérsias que "começamos a enxergar melhor o que significa fazer ciência" (COLLINS e PINCH, 2003, p. 22), pois torna-se visível para um público mais amplo o que é percebido apenas por especialistas envolvidos no debate.

\section{CONTROVÉRSIAS COMO DISPUTAS DE POSIÇÕES E DE ARGUMENTOS}

As dinâmicas de disputas em controvérsias científicas estão relacionadas a reivindicações de direitos, reconhecimento de competências e relações sociopolíticas em determinados grupos, além de outros aspectos, e revelam tensões entre autonomia individual de pesquisadoras e pesquisadores e os contextos sociais. As controvérsias oferecem significados para analisar atitudes públicas expressas pelas partes envolvidas e assumem relevância social ao relacionar-se a questões de controle sobre o desenvolvimento e a aplicação da ciência (NELKIN, 1995).

O estudo da natureza dos argumentos empregados em uma controvérsia e sua contingência permitem colocar em evidência as circunstâncias sociais que costumam ser omitidas quando um conhecimento está consolidado. Além disso, é possível perceber as influências que o contexto social exerce sobre o processo de construção e desconstrução de fatos e teorias científicas (MATTEDI, 2006). Assim, a importância metodológica de análise das controvérsias é permitir “determinar como as práticas de negociação não-científicas possibilitam a produção de conhecimento certificado e confiável” (MATTEDI, 2006, p. 174). Controvérsias científicas 
geralmente se apresentam como agrupamentos de questões que se interpõem e interessam grupos de atores diversos e heterogêneos e os motivam a participar de um debate.

Controvérsias se contrapõem a caixas-pretas e relacionam-se a dois momentos da produção e da circulação do conhecimento: a ciência em construção e a ciência pronta. Controvérsias e caixas-pretas são momentos de incerteza e certeza na construção do conhecimento, respectivamente. A caixa-preta é um conjunto de comando ou operações com conceitos complexos que são aceitos pela comunidade científica e não requerem justificação ou explicação (LATOUR, 2011). A mudança de status de controvérsia para caixa-preta ocorre quando "mais pessoas acreditam nela (a controvérsia) e a usam como caixa preta" (LATOUR, 2000, p. 72). Assim, a ciência controversa entra em sua fase de rotina, na qual uma nova ordem científica se instaura.

LATOUR (2011) compara a ciência pronta e a ciência em construção ao deus romano Janus, que possui duas faces. A face voltada para o passado orienta que os fatos científicos devem ser acatados, deve-se optar por métodos e técnicas mais eficientes e as verdades sempre se sustentam por si. A face voltada para o futuro orienta a indagação dos fatos, o conceito de eficiência deve ser questionado e as verdades somente se sustentam mediante argumentos (LATOUR, 2011).

O acompanhamento da ciência em construção, principalmente quando se estabelecem controvérsias, possibilita compreender aspectos do contexto social que estão em negociação. Tais circunstâncias deixam de ser relevantes quando o conhecimento se consolida em métodos e teorias reconhecidas.

\section{AS CONTROVÉRSIAS SOBRE MOVIMENTOS SOCIAIS DO CAMPO E SEU}

\section{CORE SET}

O estudo de controvérsias científicas requer acompanhar o modo como são abertas e como se encerram e quem delas participa. COLLINS (1974) propôs o conceito de core set para representar a rede de relações interdependentes em um grupo de participantes de um debate 


\section{Revista \\ Debates Insubmissos}

que experimenta e teoriza na fronteira da ciência. O grupo se alinha em torno de diferentes posições na convergência ou divergência de argumentos comuns defendidos (PINCH e BIJKER, 2013). A possibilidade de mapear consensos, dissensos, posições e argumentos no debate é a vantagem metodológica do uso do conceito de controvérsia.

O core set das controvérsias abordadas neste artigo é constituído por pesquisadoras e pesquisadores de universidades que investigam temas relacionados à sociedade e à política, entre eles os movimentos sociais. O sociólogo José de Souza Martins foi o desencadeador e epicentro do debate a partir de posições e argumentos apresentados em artigos científicos, capítulos de livros e artigos de jornais de circulação nacional para o qual escrevia regularmente. A posição oposta no debate foi apresentada em análises e argumentações em capítulos de livros, artigos de jornais e revista mensal de informação.

José de Souza Martins é um dos importantes sociólogos brasileiros que interpretaram a questão agrária e os movimentos sociais do campo. O sociólogo teve sua formação na Universidade de São Paulo (USP), onde atua como professor e pesquisador. Foi aluno de Florestan Fernandes e contemporâneo de Fernando Henrique Cardoso (FHC), quando professor dessa universidade.

As análises de Martins enfocaram o modo de produção capitalista no campo e os movimentos de luta pela terra ao longo da história (MARTINS, 1981, 1986). Nelas, ressaltou as permanências e mudanças nos processos sociais e políticos que acontecem no espaço rural (MARTINS, 1999). A produção científica brasileira sobre os movimentos sociais do campo encontrava, até os anos 2000, forte referencial nesse autor. Após esse período, novas pesquisadoras e pesquisadores destacaram-se no debate acadêmico sobre o tema e Martins, embora continuasse a interpretar os processos sociais do campo, passou a abordar também novos temas, como sociologia visual, vida cotidiana, função do atraso no processo político brasileiro, entre outros temas. 


\section{Revista \\ Debates Insubmissos}

Durante anos, Martins assessorou a Comissão Pastoral da Terra (CPT) a convite de dom Pedro Casaldáliga, bispo emérito de São Félix do Araguaia $^{3}$, região marcada por conflitos de terra. Ele ministrou cursos sobre formação social e política no campo para agentes pastorais e militantes dos movimentos sociais do campo. Além disso, colaborou com a Conferência Nacional dos Bispos do Brasil (CNBB). Em 1995, ele encerrou sua colaboração com movimentos sociais e afastou-se da formação de ativistas (Entrevista de Martins a Loureiro, Bastos e Rego, 2008).

$\mathrm{O}$ afastamento de Martins da assessoria aos movimentos sociais coincidiu com a colaboração ao governo do então presidente FHC, que comandou o país de 1995 a 2002, sendo indicado para integrar comissões internacionais, coordenar políticas de governo e realizar consultorias. Martins integrou a equipe de pesquisadores do Núcleo de Estudos Agrários e Desenvolvimento Rural (NEAD) do extinto Ministério do Desenvolvimento Agrário (MDA), órgão do governo federal que tinha o objetivo de subsidiar políticas públicas por meio de estudos, pesquisas, publicações, eventos etc. (MOITA, 2010). Ele também assessorou o governo em questões relacionadas à escravidão e atuou como coordenador da comissão que produziu o Plano Nacional de Erradicação do Trabalho Escravo, no Ministério da Justiça. Além disso, representou o governo brasileiro na Comissão Executiva do Fundo Voluntário contra as Formas Contemporâneas de Escravidão da Organização das Nações Unidas (ONU). O momento em que Martins colaborou com o governo FHC coincidiu com diversas análises sobre o governo, a reforma agrária e os movimentos sociais do campo que desencadearam as controvérsias analisadas adiante.

Antes de iniciar a controvérsia, uma entrevista de José de Souza Martins ao Jornal dos Trabalhadores Sem Terra, órgão de divulgação e formação do Movimento dos Trabalhadores Rurais Sem Terra (MST), de julho de 1997, permite perceber as mudanças nas análises do autor sobre o MST. Martins fez, na entrevista, uma aprofundada análise sobre a questão agrária no Brasil, a luta pela terra e sobre o lugar da reforma agrária na agenda política do país, seguindo a

\footnotetext{
${ }^{3} \mathrm{O}$ bispo foi grande defensor da reforma agrária e um dos criadores da CPT.
} 
linha de análise que realizou em seus livros mais reconhecidos. Ele explicou que o MST questiona a estrutura da propriedade e a estrutura de poder. Martins comentou que:

(...) o Movimento Sem Terra é ao mesmo tempo - e isso não tem sido discutido nem pelo MST - um grande movimento de modernização no campo. Ele é o mais consequente movimento de modernização e ressocialização das populações no campo que já houve na história do Brasil, provavelmente um dos de maior sucesso no mundo inteiro (MARTINS,1996, p. 5)

Apesar desse destaque, Martins ressaltou que o MST errava ao não mostrar que "pode tirar o sujeito da mais absoluta falta de destino, da mais absoluta miséria e transformá-lo num sujeito que vive num estado de bem-estar social" (MARTINS, 1996, p. 5).

Três anos mais tarde, Martins aprofundou as críticas e posicionamentos expressos em suas análises que deram origem às controvérsias que são objeto do presente artigo. O marco inicial foi o livro Reforma agrária: o impossível diálogo (MARTINS, 2000), que apresentou os temas geradores das controvérsias que abordaram três temas principais: anomia dos movimentos sociais, sua partidarização e a "sociologia militante". Essas controvérsias ocorreram em diferentes momentos como disputas de interpretações. Os temas indicados por Martins, e objeto de contra-argumentação entre os demais participantes do debate, são recortes metodológicos para compreender a disputa nas controvérsias. A seguir, será caracterizada a concepção de Martins acerca dos temas para, em seguida, apresentar como as controvérsias se desenrolaram.

A primeira controvérsia é anunciada no argumento de Martins (2000) sobre a anomia dos movimentos sociais e organizações populares do campo: MST, Confederação Nacional dos Trabalhadores na Agricultura (Contag) e CPT. Segundo o autor, essas organizações são dirigidas por militantes de origem pequeno-burguesa e não raro por intelectuais sem vínculo com a terra ou a agricultura. Trata-se de uma classe social que assumiu discurso e prática radicalizados enquanto os trabalhadores rurais objetivamente desejam conquistar terra para ter melhores condições de vida. Assim ele caracterizou a anomia dos movimentos sociais: os representantes de uma classe social assumem a direção do movimento de outra classe. Martins afirmou que se trata de uma tutela iluminista dos pobres desvalidos, reflexo de uma cultura "gestada na casa-grande, muito mais expressão de uma mentalidade de culpa, pena e caridade 


\section{Revista \\ Debates Insubmissos}

do que de uma mentalidade revolucionária" (MARTINS, 2000, p. 106), na qual as direções colocaram o projeto de transformação social acima da realização da reforma agrária.

Martins destacou estar em desacordo com essa ideologização (MARTINS, 2000). Para ele, tal situação ocorre porque o protagonista real não tem condições históricas de se interpretar diretamente (MARTINS, 2000). Ele afirmou que "os que lutam pelos trabalhadores rurais querem uma reforma agrária confiscatória e punitiva para o latifúndio" (MARTINS, 2000, p. 110), de modo que as dívidas do passado sejam pagas na atualidade. $\mathrm{O}$ autor destacou que o MST e sua aliada CPT querem o confisco das propriedades e não aceitam menos que isso. Afirmou que esses mediadores da luta social propõem reforma agrária radical inspirada nos marcos de revolução socialista (MARTINS, 2000).

A segunda controvérsia, anunciada por Martins, é a partidarização dos movimentos sociais do campo, a partir da aproximação do MST e da CPT com o Partido dos Trabalhadores (PT). Martins afirmou que o Partido utilizou os movimentos sociais do campo como base para sua expansão a partir da politização da reforma agrária. Para ele, o PT, ao apoiar as lutas durante a formação destas organizações, usou-as para crescer e estabelecer uma base política no campo para desqualificar o Estado, plasmado por Martins nas ações de política agrária do então governo Federal. À época, seu colega de universidade, Fernando Henrique Cardoso, era presidente da República (MARTINS, 2000).

Para exemplificar esse contexto, ele analisou as ações do governo FHC para equacionar a oferta e demanda de terras para a reforma agrária, quais sejam: regularização fundiária, desapropriação de terras e incentivo à agricultura familiar. Martins (2000) destacou a crítica do MST e da CPT, juntamente com o PT, de que aquelas ações não são de reforma agrária e não deveriam ser contabilizadas como tal, mas somente a desapropriação de terras para implantação de assentamentos. Ele contra-argumentou que a regularização é um ato legítimo de reforma agrária e relembrou a luta de posseiros contra grileiros e a expulsão da terra por não terem títulos de propriedade de suas terras. Ele ressaltou que a criação de assentamentos é a forma de redistribuição da terra essencial de qualquer reforma agrária, porém, deve ser considerada para a mudança da estrutura agrária "todo ato tendente a desconcentrar a propriedade da terra quanto 


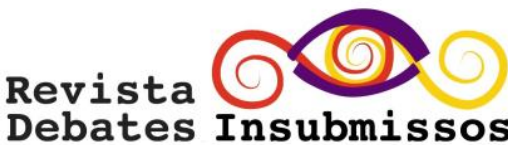

esta representa ou cria um impasse histórico ao desenvolvimento social baseado nos interesses pactuados da sociedade" (MARTINS, 2000, p. 102).

A terceira controvérsia é o que Martins define como "sociologia militante", presente no meio acadêmico. Para ele, há um desejo de pesquisadoras e pesquisadores de instrumentalizar argumentos para a defesa do MST. Trata-se, a seu ver, de um desejo de participar de um confronto que, na percepção dessas pesquisadoras e pesquisadores, poderá fazer história. $\mathrm{O}$ autor chamou a atenção que fazer ideologia não é ciência social e exemplificou o caso de jovens pesquisadoras e pesquisadores alinhados com o MST, cujos "objetos" de estudo são alinhados aos interesses do Movimento. Ele comentou que jovens que estão cursando mestrado ou doutorado escolhem temas politizados, como reforma agrária, e que raramente, na sua opinião, surgiam contribuições relevantes. Tratava-se, segundo sua análise, de discursos articulados, mas quase sempre interpretações que "resvalam perigosamente para uma ideologia pura (...) mergulhados em uma justificativa alucinada de tudo que o MST faz" (MARTINS, 2008, p. 73).

Em perspectiva oposta, Martins afirmou que o pesquisador deve "lidar com a dimensão apropriada do tempo dos processos sociais que examina" (MARTINS, 2008, p. 73). Ele destacou que a sociologia é a ciência que reflete sobre a possibilidade do pensamento crítico que "não se pode fechar certeza, mas, também não se pode fechar incerteza" (MARTINS, 2008, p. 73). Ele alertou que pesquisar requer conhecer o campo de estudo com profundidade, mas deve abrir a possibilidade da dúvida a respeito do que já conhece, porque o processo no qual se está conhecendo altera o conhecimento já consolidado e as condições de produção de novos conhecimentos.

Esses temas de controvérsias foram contrapostos por pesquisadoras e pesquisadores de universidades brasileiras. A maior parte dos questionamentos ocorreu por meio de artigos dos jornais Folha de S. Paulo e O Estado de São Paulo e da revista Caros Amigos (VILLA, 2001; SILVEIRA, 2005; ARBEX Jr., 2005), registrada em teses e dissertações acadêmicas (ALVES, 2003; MOITA, 2010) e resenha de livro (SOTO, 2002). As controvérsias foram retomadas mais recentemente em capítulos de livros que discutem a desigualdade social, o MST e a reforma agrária no Brasil, resultado de evento realizado no Centre for Brazilian Studies, da Universidade 
de Oxford (CARTER, 2010). Parte significativa das manifestações de Martins ocorreu em artigos que escrevia no jornal O Estado de São Paulo (MARTINS 2001, 2005a, 2005b, 2006 e 2009).

A seguir será comentado como essas controvérsias foram objeto de debates entre Martins e diferentes pesquisadoras e pesquisadores, destacando como se apresentaram em argumentos e contra-argumentos.

\section{A RECONSTRUÇÃO DAS CONTROVÉRSIAS}

O afastamento de Martins da assessoria aos movimentos sociais coincidiu com o período no qual ele passou a criticar a CPT e o MST. Também coincidiu com o período em que fez análises das ações do governo FHC em relação à reforma agrária (MARTINS, 2003).

Após o lançamento do livro Reforma agrária: o impossível diálogo, o debate sobre as controvérsias tem o primeiro questionamento apresentado em um artigo jornalístico que comentou o livro e que traz as controvérsias indicadas por Martins. O artigo é de Marco Antonio Villa, pesquisador de história do Brasil e latino-americana e professor da Universidade Federal de São Carlos (UFSCar). Ele criticou as análises de Martins por meio de uma resenha. Villa (2001) analisou, de modo destacado, a crítica de Martins ao MST e à CPT por rejeitarem a legitimidade do Estado, impossibilitando as negociações com o governo federal que poderiam acelerar a reforma agrária. Ele afirmou que a crítica tem "tom rancoroso" de Martins por não ser "mais ouvido pelas lideranças" como era nas décadas de 70 e 80 . destacou ainda que Martins assumiu o papel de um "sociólogo complacente com o poder" ao desqualificar a ação do MST e ao ignorar o massacre de camponeses de Eldorado do Carajás ${ }^{4}$ (VILLA, 2001).

Villa afirmou, ainda, que a postura de Martins está muito distante do autor de clássicos da sociologia que interpretam o rural brasileiro e a luta pela reforma agrária. Também ressaltou que aguardava o desenrolar da polêmica e a considerava “extremamente saudável” para o debate sobre

\footnotetext{
${ }^{4}$ Conflito entre sem terras e policiais, ocorrido em 1996, em que resultou na morte de 21 manifestantes em decorrência da violenta repressão policial.
} 


\section{Revista \\ Debates Insubmissos}

os rumos da reforma agrária. Concluindo a crítica, ele afirmou que a crítica receberá a "devida resposta” do MST e da CPT (VILLA, 2001). A resposta nunca foi publicamente dada.

A resposta de Martins (2001) ao artigo de Villa também foi apresentada em artigo de jornal, no qual caracterizou-o como uma "crônica tendenciosa" e que "desperdiçou uma boa oportunidade de dar uma demonstração de competência teórica" (MARTINS, 2001, s/p) ${ }^{5}$. Ele criticou o método de análise de seu crítico afirmando que "recorta arbitrariamente os temas, seleciona o que interessa, junta o que não está junto e monta um discurso ideológico sobre aquilo que lhe convém dizer" (MARTINS, 2001, s/p). Ele retomou a controvérsia sobre a sociologia militante e argumentou que Villa fez uma interpretação de que o mundo do conhecimento sobre a sociedade que está dividido entre "os que optam pelo MST e os que optam pelo governo" (MARTINS, 2001, s/p).

Martins afirmou recusar-se ao "aplauso gratuito, oportunista e demagógico" (MARTINS, 2001, s/p) ao MST e à CPT e criticou os pesquisadores dessas organizações ao destacar que necessitavam "aprofundar o conhecimento crítico sobre sua própria ação" (MARTINS, 2001, s/p). Ele defendeu-se da acusação de apatia aos conflitos no campo e de ser um "sociólogo complacente com o poder" argumentando que suas análises assinalam o indispensável papel do Estado na mudança da estrutura agrária (MARTINS, 2001). Por fim, criticou os pesquisadores dos movimentos sociais por confundirem a "necessária militância do cidadão com a transformação do conhecimento crítico em conhecimento conivente e panfletário.” (MARTINS, 2001, s/p).

Na resposta a Villa, Martins retomou a controvérsia de anomia dos movimentos sociais do campo, ao destacar que seu livro Reforma Agrária: impossível diálogo não é propriamente sobre reforma agrária, mas uma análise do desencontro entre o projeto revolucionário dos militantes do MST e da CPT com o projeto de reprodução camponesa familiar dos

\footnotetext{
${ }^{5}$ A maior parte da pesquisa dos artigos dos participantes das controvérsias foi realizada no acervo digital dos jornais mencionados, conforme indicado nas referências bibliográficas, nos quais, na maioria das vezes, não é informada a página da publicação. Não há norma na Associação Brasileira de Normas Técnicas (ABNT) que oriente fazer referência às páginas de citações em tais caso. Em razão desta peculiaridade dos dados, o número da página da citação será substituído por "s/p" quando for o caso.
} 
trabalhadores rurais (MARTINS, 2001). Ele ressaltou que as lutas sociais dirigidas pelo MST, pela CPT e pela Contag representavam um ganho histórico e uma barreira à reprodução ampliada do capital, porém, se perderam no "redutivismo da retórica supostamente revolucionária (e no) desconhecimento da própria ação” (MARTINS, 2001, s/p).

A controvérsia da sociologia militante foi retomada por Martins em artigo de jornal que comentou a criação da Escola Nacional Florestan Fernandes, do MST (MARTINS, 2005a). O objetivo do artigo foi criticar a homenagem como "uso e manipulação" do nome de Florestan por razões político ideológicas e comentou que não saberia se o homenageado se sentiria feliz como patrono de uma escola cuja orientação estaria em completo desacordo com o que escreveu e ensinou (MARTINS, 2005a). O tema do artigo foi a "ideologização" na sociologia do conhecimento, concepção que, segundo Martins, concorreria com toda a tradição das ciências sociais, "em nome do militantismo e da negação da sociologia como conhecimento científico e crítico, isto é, conhecimento situado, com as condições sociais de sua referência e produção" (MARTINS, 2005a, s/p).

Ele apontou que a inferência de que Florestan foi um apóstolo da "sociologia militante" estaria em desacordo com sua obra. Martins comentou que Florestan foi

[...] bastante conservador na maioria de seus textos quanto à postura que adotava em relação à produção do conhecimento científico (situação a qual) nunca o privou da consciência sociológica de sua postura científica, mesmo no positivismo, pautada na neutralidade ética, já poderia ser uma postura política de compromisso social (MARTINS, 2005a, s/p).

A resposta a Martins veio de Heloísa Fernandes Silveira, também professora da USP e filha de Florestan, que representou a família no ato de inauguração da Escola Nacional Florestan Fernandes. Ela rebateu as considerações de Martins acerca da distinção militância e produção do conhecimento científico relacionada à controvérsia da sociologia militante em artigo da revista Caros Amigos (SILVEIRA, 2005). Afirmou ter havido, nas posições de Martins, um preconceito que não consegue dissimular (SILVEIRA, 2005). A pesquisadora considerou discutível a transformação da vida e obra de Florestan Fernandes em objeto que justifique a pretensão de preservar a "pureza sociológica acadêmica", tornando Florestan em um "prisioneiro do campus universitário". Ela complementou que uma das mais fortes aspirações da vida de Florestan foi 
romper com o espírito elitista que faz com que o intelectual se acostume a servir às elites (SILVEIRA, 2005). A pesquisadora fez o comentário sem indicar o nome de Martins como o intelectual que serve às elites, apesar de o artigo ser uma resposta às argumentações de Martins.

A controvérsia sobre a partidarização dos movimentos sociais do campo foi retomada durante as comemorações do aniversário de 21 anos do MST e que coincidiu com o primeiro governo de Lula na presidência da República, em 2003. O MST organizou a Marcha Nacional pela Reforma Agrária, com destino à Brasília, que teve o objetivo de apresentar demandas do MST ao governo Federal e ao Congresso Nacional. Em razão da repercussão da mobilização, o jornal Folha de S. Paulo convidou o jornalista José Arbex Júnior, professor da Pontifícia Universidade de São Paulo, e José de Souza Martins, para responderem à pergunta se o MST seria um movimento social autônomo. Os artigos não são um debate direto entre os convidados, mas traduziram a intenção do jornal em evidenciar a disputa de posições sobre o tema com os dois autores que retomaram posições opostas na controvérsia sobre a partidarização dos movimentos sociais, de modo destacado o MST.

Arbex Jr. (2005) argumentou que o MST era independente em relação ao governo federal e ressaltou que a luta do Movimento é histórica por dois motivos. O primeiro era a luta do MST para abolir a "escravidão dos pobres" ao capital e ao latifúndio. O segundo era relacionado ao fato de o MST fazer história por ser um movimento de camponeses que se organizou em escala, por mais tempo e criou diversos vínculos com a sociedade civil (ARBEX JR. 2005).

Em perspectiva oposta, Martins (2005b) respondeu à pergunta do jornal afirmando que o MST não é uma organização política autônoma, nem é um movimento social. Para ele, o Movimento é uma expressão de uma "modernidade anômala" de países com grandes desencontros entre o desenvolvimento econômico e o desenvolvimento social, em que "populações retardatárias da história emergem nas brechas do sistema político e apresentam, de forma ritualmente tradicionalista, suas demandas sociais aparentemente extemporâneas" (MARTINS, 2005b, s/p). Ele ressaltou que as demandas são "atrasadas e fora de época (e que) a organização assume a aparência de uma autonomia que não é real" (MARTINS, 2005b, s/p). Martins comentou que "a reivindicação oculta da Marcha atendeu a uma necessidade do 
governo: dar visibilidade para os seus êxitos, ainda que limitados, na questão agrária" (MARTINS, 2005b, s/p) e para mostrar-se como governo aberto às reivindicações dos trabalhadores rurais (MARTINS, 2005b).

Ele acrescentou que o MST é uma "organização constitutiva" do PT, uma "base do partido" e que, sem o Movimento, "dificilmente o PT teria se expandido tão extensamente no interior e dificilmente se tornaria o único partido brasileiro com uma ampla base rural e popular" (MARTINS, 2005b, s/p), retomando a controvérsia sobre a partidarização dos movimentos sociais do campo. Martins comentou ainda que o MST decidiu refrear as manifestações e as ocupações de terra durante a campanha eleitoral de Lula para não prejudicar a candidatura petista e associá-la a radicalismos. Por fim, ele ressaltou que "o MST não se move apenas com base em ideologia política, mas sobretudo com base na mística milenarista de um tempo de redenção dos pobres e oprimido" (MARTINS, 2005b, s/p). A afirmação vai no sentido contrário ao caráter moderno que ele conferiu ao Movimento na entrevista ao Jornal dos Trabalhadores Sem Terra, em 1996, citada anteriormente. Naquele momento, ele havia ressaltado a atuação do MST em retirar a população pobre do campo da falta de destino, da miséria e transformá-la em sujeito de um Estado de bem-estar social (MARTINS, 1996).

A controvérsia sobre a partidarização dos movimentos sociais do campo foi mais uma vez retomada por Martins em 2006. Ele comentou em artigo de jornal que, ao se envolver com a política partidária, o MST interferiu positivamente no processo político brasileiro ao romper com o laço que atou a testa das populações do campo ao "mourão da porteira" dos líderes políticos tradicionais (MARTINS, 2006). Por outro lado, considerou que o sentido libertador dessa interferência se perdeu na constituição dos "currais eleitorais" do PT que partidarizaram sem politizar e sem emancipar. Tratava-se de uma relação de "toma lá e dá cá" com o PT e o governo Lula, salientou Martins (2006).

A retomada das controvérsias sobre a anomia e a partidarização dos movimentos sociais do campo ocorreu mais uma vez em artigo que comentou declaração de um dirigente do MST, durante aniversário de 25 anos do movimento, em 2009. Martins (2009) fez o retrospecto da relação entre a Igreja católica e a luta pela terra, que considerou ser a gênese do MST. Sobre a 
controvérsia da anomia dos movimentos sociais, ele comentou que "a reforma agrária nada tem de revolucionária, embora possa ter potenciais de transformação social e até política" (MARTINS, 2009, s/p) e ressaltou que a agricultura familiar é o sujeito social da reforma agrária. Ele retomou o capital social do MST que é desperdiçado quando se reduz a

[...] uma prática fantasiosa, destituída de mediações e imune às próprias contradições. Ao ignorar os limites e as possibilidades desse dilema, o MST deixa de tirar dele mais do que a bravata anticapitalista de seus dirigentes e atira ao monturo das oportunidades perdidas a riqueza do capital social (MARTINS, 2009, s/p)

Sobre a controvérsia sobre a partidarização dos movimentos sociais, em particular do MST, Martins comentou que o Movimento

[...] se apropriou da cultura das lutas pela terra e unificou [...] política e ideologicamente a imensa variedade de lutas pela terra em todo o Brasil (e o MST foi) a base da afirmação partidária do PT no campo, propondo-se como mediação partidária única na diversidade rural" (MARTINS, 2009, s/p).

As controvérsias sobre os movimentos sociais do campo tiveram desdobramento recente, com a publicação do livro Combatendo a desigualdade social - o MST e a Reforma Agrária no Brasil (CARTER, 2010a), que contém artigos de diversos especialistas em questão agrária e movimentos sociais e foram apresentados em uma conferência internacional na Universidade de Oxford, conforme já antecipado, em 2003. Os dois artigos que se destacam na crítica às análises de Martins São de Rosa (2010) e Carter (2010b).

O artigo de Rosa (2010) argumentou, a partir de estudo que realizou sobre o MST no estado de Pernambuco, que a realidade dos movimentos sociais do campo rompe com o estereótipo do engajamento somente por terra para a reprodução social da família camponesa, conforme análise proposta por Martins. O autor argumentou que a participação na luta pela terra está ligada a processos sociais de ruptura com os padrões tradicionais de hierarquia social. Ao contrário do que afirmou Martins ao destacar o tradicionalismo do camponês, Rosa argumentou que "tomar parte dos pequenos e grandes movimentos da região significa, sobretudo, diferenciarse socialmente por meio da construção de novos espaços políticos e, principalmente, pelo contato com novos valores sociais" (ROSA, 2010, p. 475).

Rosa também se posicionou em relação à controvérsia sobre a "sociologia militante" e criticou Martins por analisar os processos sociais agrários a partir de "camponeses idealizados" 


\section{Revista \\ Debates Insubmissos}

para "manter seu próprio lugar na história como intelectual de uma sociologia do homem simples" (ROSA, 2010, p. 475). Ele também criticou sociólogos que, nos debates sobre reforma agrária, usam da idealização do camponês como uma estratégia política para conservação do status de verdade em teorias parciais que se pretendem universais (ROSA, 2010).

Carter (2010b), por sua vez, retomou a controvérsia da anomia dos movimentos sociais e criticou Martins por sua afirmação de que o MST não reconhece a legitimidade institucional e as ações do Estado. Ele afirmou também que as afirmações de Martins são "grosseiras simplificações" e "ataques gratuitos" ao MST, nas palavras do autor, e sem evidências empíricas que fundamentem muitas de suas análises. Ele sugere que se trata de difundir uma "retórica da intransigência". Acrescentou ainda que Martins, e outros críticos do MST, não tratam das desigualdades sociais no Brasil como problema analítico central (CARTER, 2010).

A controvérsia de partidarização do MST foi retomada por Carter que se posicionou acerca do argumento de Martins de que o MST não reconhecia a legitimidade institucional e as ações do Estado durante o governo FHC. Carter (2010) contra-argumentou que as políticas de reforma agrária daquele governo foram mais reativas e menos propositivas, ao contrário do que considera Martins (CARTER, 2010). O foco da intervenção governamental foi pacificar os conflitos no campo e evitar confronto com as elites agrárias (CARTER, 2010). Ele destacou ainda que as ações de governo foram resultado de crescentes mobilizações do MST e de dois massacres de Sem Terra realizados por policiais ${ }^{6}$. O pesquisador ressaltou, também, a omissão de Martins acerca da implantação de propostas neoliberais pelo governo $\mathrm{FHC}$, dentre elas a "reforma agrária de mercado"7 para desmobilizar a luta pelas desapropriações. Carter (2010) reiterou que as análises de Martins eram descontextualizadas e tiraram o foco analítico da racionalidade das ações do MST. Martins não respondeu à contraposição desses pesquisadores.

\footnotetext{
${ }^{6}$ Referência aos episódios de Corumbiara, em 1995, e Eldorado dos Carajás, ocorrido em 1996, que resultaram em mortes de manifestantes do MST.

${ }^{7}$ Proposta concebida e financiada pelo Banco Mundial com o objetivo de resolver o problema agrário por meio do mercado de terras. Os problemas estruturais do acesso à terra seriam resolvidos em uma relação de compra e venda de terras.
} 


\section{ANÁLISE dAS CONTROVÉRSIAS NA CONSTRUÇÃO DO CONHECIMENTO CIENTÍFICO SOBRE OS MOVIMENTOS SOCIAIS DO CAMPO}

As controvérsias entre pesquisadoras e pesquisadores permitem compreender aspectos de como ocorrem as disputas de posições e argumentos na produção do conhecimento. O recorte metodológico das três controvérsias, quais sejam, sociologia militante, anomia e partidarização dos movimentos sociais do campo, teve como objetivo analisar o debate que é pouco destacado nos estudos dos atores sociais do campo e seu significado na produção e disseminação do conhecimento científico nas ciências humanas. A análise das controvérsias analisadas neste trabalho permitiu compreender como surgiu a disputa na comunidade científica, quem participou, como se ampliou para a opinião pública e as relações com o contexto social e político.

As controvérsias selecionadas no artigo foram iniciadas em um cenário de mudança nos estudos sobre os movimentos sociais do campo. A produção teórica nessa área tinha importantes autoras e autores até os anos 2000, entre as quais a contribuição de Martins faziam parte. Os movimentos sociais tornaram-se tema de diversas áreas de conhecimento, sob diferentes perspectivas, não somente nas ciências sociais, e por diferentes pesquisadoras e pesquisadores. Foi nesse ambiente de diversidade de abordagens e temas relacionados aos movimentos sociais do campo que Martins elaborou interpretações que questionaram a atuação desses atores sociais.

Os debates começaram no espaço acadêmico, por meio do livro Reforma Agrária: impossível diálogo, e ampliaram-se para a sociedade por meio de artigos de jornais e revista dirigidos ao público em geral. Os participantes das controvérsias, pesquisadoras e pesquisadores de universidades, foram convidados por esses meios de comunicação de massa para abordar temas e fatos. Assim, as controvérsias abordadas nesta pesquisa seguiram o movimento de muitas controvérsias científicas que se iniciaram no ambiente acadêmico e, em razão do interesse social, tornaram-se objeto de debate público.

Identificou-se na pesquisa o core set que participou das controvérsias e oportunizou o precursor da disputa, José de Souza Martins, debater os temas por ele indicados. A motivação para a participação, no debate, de pesquisadoras e pesquisadores cujos objetos de estudos eram relacionados aos temas das controvérsias, foi a crítica de posições assumidas por Martins. É o 
caso de Villa, Rosa e Carter. Outros participantes das controvérsias, Arbex Jr. e Silveira, atuaram de forma eventual a partir de fatos específicos, como a comemoração de 21 anos do MST e a inauguração da Escola Nacional Florestan Fernandes.

A repercussão da controvérsia pode ser associada ao papel e atuação do MST no quadro político-institucional brasileiro. O Movimento, apesar da diminuição do interesse da opinião pública pela reforma agrária, foi, e ainda é, um ator social que, por meio de sua visibilidade pública, destaca, nas suas pautas e mobilizações, os temas da justiça e desigualdade social no campo. Ao longo do tempo, Martins concentrou suas críticas no MST, abandonando a CPT e a Contag, que continuaram a ter importante atuação nas lutas sociais do campo, embora desconsideradas pelo pesquisador durante o desenrolar das controvérsias.

O contexto social e político no qual aconteceu o surgimento das controvérsias foi caracterizado pelo fortalecimento dos movimentos sociais do campo e o acirramento dos embates com o governo Federal, sob a gestão de FHC. Entre as ações desse governo estiveram a redução da intervenção estatal na economia, por meio da extinção e privatização de empresas públicas, e o repasse de atribuições governamentais para a iniciativa privada como desdobramentos do projeto neoliberal no Brasil.

Esse cenário marcou fortemente o debate sobre a relação da sociedade civil, e o MST em particular, com o Estado, de modo destacado as ações de governo sobre a reforma agrária. Martins pouco aborda esse contexto nas controvérsias sobre os movimentos sociais do campo, embora tenha sido o período em que as controvérsias eclodiram. Elas tornaram-se mais evidentes nos anos seguintes.

Por outro lado, Martins citou as iniciativas do governo FHC, cujos objetivos relacionaram-se com a reforma agrária, como regularização fundiária, desapropriação de terras, políticas de apoio à agricultura familiar, entre outras. Entretanto, ele não abordou uma das principais propostas de cunho neoliberal desse governo que foi a "reforma agrária de mercado". A proposta se constituiu em um mecanismo de financiamento público que possibilitou o acesso a terras por meio de negociação direta entre o proprietário e os agricultores sem-terra. Assim, o mercado tornou-se alternativa à atuação do Estado na 


\section{Revista \\ Debates Insubmissos}

redistribuição de terras por meio da desapropriação. Houve muitos embates em torno da atuação do governo FHC nessa disputa de política fundiária, uma delas foi seu caráter neoliberal e outra foi a tentativa de desmobilização dos movimentos sociais do campo para a ocupação de terras. Martins não aborda essas questões nas controvérsias.

Os participantes da disputa fizeram uso de suas trajetórias de engajamento social, reputação, de sua credibilidade como cientistas e do recurso da argumentação para defender suas posições. As pesquisadoras e os pesquisadores utilizaram essas estratégias com o objetivo de afirmar suas interpretações, por meio de sua justificação, além da rejeição dos argumentos de Martins. Esse, por sua vez, utilizou as estratégias de evidenciar o debate na comunidade acadêmica e na opinião pública em geral e de abordar recorrentemente os temas das controvérsias, utilizando meios de comunicação de massa para publicizar seus argumentos.

Martins também recortou situações e fatos como estratégia para fortalecer seus argumentos e posições nas controvérsias. Um desses recortes definiu focos analíticos e excluiu outros, como na controvérsia sobre a partidarização dos movimentos sociais do campo. O recorte no MST privilegiou a relação que o Movimento construiu com o PT desde sua fundação. Por outro lado, o argumento de que o MST e a CPT foram a base de crescimento do PT no campo demonstra o recorte intencional para privilegiar sua posição. Martins desconsiderou a relação de outros movimentos, como os sindicatos da Contag, que possuem grande distribuição no país, muito maior do que o MST, e podem ter contribuído muito mais para a estruturação do Partido no interior do país. Os sindicatos de trabalhadores rurais distribuem-se na maioria dos municípios país, enquanto o MST que atua somente em áreas de conflito de terra e assentamentos rurais.

Ao criticar a sociologia militante, Martins abandonou a simetria necessária na produção do conhecimento científico. Ele criticou pesquisadoras e pesquisadores alinhados com os movimentos sociais do campo, mas não assumiu que muitas de suas críticas refletiram seu posicionamento político na produção do conhecimento científico, conforme indicada por Villa ao referir-se à "complacência com o poder", ao criticar veladamente a relação de Martins com o então governo FHC. 


\section{Revista \\ Debates Insubmissos}

As estratégias utilizadas por Martins objetivaram alcançar a estabilização da controvérsia, momento em que posições se tornam vencedoras do debate por meio da concordância do maior número possível de pesquisadoras e pesquisadores ou da desistência de opositores. O meio para alcançar este objetivo foi a ampliação das controvérsias para o domínio público. Seu êxito foi parcial. Ele conseguiu chamar atenção para temas e manter-se como referência no debate sobre movimentos sociais, no entanto as controvérsias parecem permanecer abertas.

\section{CONCLUSÕES}

O objetivo deste artigo foi analisar como fatores extra científicos influenciam a validação e a aceitação de argumentos em uma comunidade acadêmica em que há disputa de argumentos e interpretações como controvérsias.

O trabalho demonstrou a relevância da identificação de interesses mobilizadores nas controvérsias na produção e circulação do conhecimento científico para alcançar maior visibilidade e reconhecimento da comunidade acadêmica. Martins, embora já reconhecido como um dos importantes sociólogos em estudos agrários, buscou lançar suas análises sobre os movimentos sociais do campo na atualidade e, ao mesmo tempo, retomar a posição de uma das principais referências no debate, que ocupava até os anos 2000. Esse interesse orientou estratégias para evidenciar posições e argumentos em diferentes fóruns de debate, seja em publicações científicas, seja em meios de comunicação para o público em geral.

As controvérsias resultantes do debate sobre os argumentos de Martins com pesquisadoras e pesquisadores e sua contextualização no ambiente social e político possibilitaram compreender o papel dos fatores extra científicos no trabalho acadêmico. Evidenciam essa situação a relação entre os argumentos do autor com a aproximação do governo à época e as críticas reiteradas aos movimentos sociais do campo que se contrapunham às ações daquele governo. 
Outro aspecto da relação entre fatores extra científicos, a produção e a circulação do conhecimento científico é a crítica e a assunção da sociologia militante caracterizada por Martins. Ele reivindicava imparcialidade e objetividade na análise dos processos sociais do campo, mas contraditoriamente caiu na armadilha de também fazer uma sociologia relacionada a seus interesses acadêmicos e relações sociais e políticas, ao omitir críticas às ações de governo que visavam a desmobilização da luta pela terra e realçavam aspectos críticos dos movimentos sociais do campo.

O estudo das controvérsias permitiu perceber que o conhecimento científico não é validado somente por uma postura científica rigorosa, mas o é, também, pela articulação de interesses e relações sociais e políticas nos quais ocorrem a produção e circulação do conhecimento. Desse modo, verificou-se que a atividade científica pode ser influenciada por situações sociais. A pesquisa também permitiu compreender que imparcialidade e objetividade podem perder força explicativa diante de mediações sociais na produção e circulação do conhecimento científico.

\section{REFERÊNCIAS}

ALVES, Juliete M, A Reforma Agrária nas obras de José de Souza Martins: uma leitura Sociológica. 2003. Dissertação (Mestrado em Desenvolvimento Rural) - Programa de Pósgraduação em Desenvolvimento Rural, Universidade Federal do Rio Grande do Sul, Porto Alegre, 2003.

ARBEX Jr. José. Um movimento contra a escravidão. O Estado de São Paulo. 21 de mai. de 2005. Disponível em https://www1.folha.uol.com.br/fsp/opiniao/fz2105200509.htm. Acessado em 20 de out. de 2020.

CARTER, Miguel (org.). Combatendo a desigualdade social: o MST e a Reforma Agrária no Brasil. São Paulo: Editora Unesp, 2010a.

CARTER, Miguel. Desafiando a desigualdade: contestação, contexto e consequências. In CARTER, Miguel (org.). Combatendo a desigualdade social: o MST e a Reforma Agrária no Brasil. São Paulo: Editora Unesp, 2010b. 
COLLINS, Harry. Mudando a ordem: replicação e indução na prática científica. Belo Horizonte: Fabrefactum, 2011.

COLLINS, Harry e PINCH, Trevor. O Golem: o que você deveria saber sobre ciência. São Paulo: Editora Unesp, 2003.

COLLINS, Harry e PINCH, Trevor. The TEA Set: tacit knowledge and scientific networks. Social Studies of Science, v. 4, n. 2, p. 65-86, abr. 1974.

KUHN, Tomas. S. A estrutura das revoluções científicas. São Paulo: Perspectiva, 1998.

LATOUR, B. Ciência em ação: como seguir cientistas e engenheiros sociedade afora. São Paulo. Editora UNESP, 2011.

MARTIN, Brian e RICHARDS, Evelleen. Scientific knowledge, controversy and public decision making. In JASANOFF, Sheila, MARKLE, Gerald E., PETERSEN, James C. e PINCH, Trevor. Handbook of science and technology studies. Thousand Oaks, Londres, Nova Déli: Sage Publications, 1995.

MARTINS, José de Sousa. Os camponeses e a política no Brasil: as lutas sociais no campo e seu lugar no processo político. Petrópolis: Vozes, 1981.

MARTINS, José de Sousa. O Cativeiro da Terra. São Paulo: Hucitec, 1986.

MARTINS, José de Sousa. O poder do atraso: ensaios da sociologia da história lenta. São Paulo: Hucitec, 1999.

MARTINS, José de Sousa. Reforma agrária ameaça a base do poder do latifúndio. Entrevista concedida a Débora Lerrer. Jornal dos Trabalhadores Sem Terra, n. 160, p. 3-5, jul. 1996.

MARTINS, José de Sousa. Reforma agrária: o impossível diálogo. São Paulo: Edusp, 2000.

MARTINS, José de Sousa. Dilemas de interpretação. Folha de São Paulo. 25 de fev. .2001. Disponível em <https://www1.folha.uol.com.br/fsp/mais/fs2502200113.htm>. Acessado em 12 de out. de 2020.

MARTINS, José de Sousa. A reforma agrária no segundo mandato de Fernando Henrique Cardoso. Tempo Social, São Paulo. v. 15, n. 2, p. 141-175, nov. 2003.

MARTINS, José de Sousa. Uma escola com o nome de Florestan Fernandes. O Estado de S. Paulo. 6 de fev. 2005a.

MARTINS, José de Sousa. A dependência oculta. O Estado de São Paulo. 12 de mai. de 2005b. Disponível em <https://www1.folha.uol.com.br/fsp/opiniao/fz2105200508.htm>. Acessado em 20 de out. 2020.

MARTINS, José de Sousa. A trama de contradições do MST. O Estado de São Paulo. 17 de 
set. 2006.

MARTINS, José de Sousa. Mística e contradições do MST. O Estado de São Paulo. 24 de jan. de 2009. Disponível em <https://alias.estadao.com.br/noticias/geral,mistica-econtradicoes-do-mst,312518>. Acessado em 23 de out. de 2020.

MARTINS, José de Sousa. Relatório de Pesquisa No 11/2008, São Paulo, p. 46-75, 2008. Entrevista concedida a Maria Rita Loureiro, Elide Rugai Bastos, José Marcio Rebolho Rego. Disponível em <https://bibliotecadigital.fgv.br/dspace/bitstream/handle/10438/2952/Rel112008.pdf?sequen ce $=1 \&$ isAllowed=y $>$. Acessado em 19 de dez. 2020.

MATTEDI, Marcos. A. Sociologia e conhecimento: introdução à abordagem sociológica do problema do conhecimento. Chapecó: Argos, 2006.

MATTEDI, Marcos. Sociologia da ciência: temas, problema e abordagens. Blumenau: Edifurb, 2017.

MOITA, Guilherme M. As Críticas de José de Souza Martins aos mediadores de esquerda dos movimentos sociais agrários. Tese (Doutorado em Doutor em Ciências Sociais). Instituto de Ciências Humanas e Sociais Curso de Pós-graduação Em Desenvolvimento, Agricultura e Sociedade, Universidade Federal Rural do Rio de Janeiro, Rio de Janeiro, 2010.

NELKIN, Dorothy. Science controversies: the dynamics of public dispute in United States. In JASANOFF, Sheila, MARKLE, Gerald E., PETERSEN, James C. e PINCH, Trevor. Handbook of science and technology studies. Thousand Oaks, Londres, Nova Déli: Sage Publications, 1995.

PINCH, Trevor. J.; BIJKER, Wiebe. E. La construcción social de hechos y de artefactos: o acerca de cómo la sociología de la ciencia y la sociología de la tecnología pueden beneficiarse mutuamente. In: THOMAS, Hernán e BUCH, Alfonso. Actos, actores y artefactos: sociología de la tecnologia. Bernal: Universidad Nacional de Quilmes, 2013.

ROSA, Marcelo C. Para além do MST: o impacto dos movimentos sociais brasileiros. In CARTER, Miguel (org.). Combatendo a desigualdade social: o MST e a Reforma Agrária no Brasil. São Paulo: Editora Unesp, Centre for Brazilian Studies, Universidade de Oxford, NEAD, MDA, 2010.

SILVEIRA, Heloísa F, Florestan Fernandes, universidade e MST. Caros Amigos, São Paulo, Ano VIII, nº 96, mar. de 2005.

SOTO, William H. G. Reforma agrária: o impossível diálogo. Sociologias, Porto Alegre, RS, ano $4, n^{\circ}$ 7, p. 272-277, jan/jun 2002. Resenha. 
VALERIO, Palmira. M. e PINHEIRO, Lena. V. R. TransInformação, Campinas, v. 20, n. 2, p.159-169, mai./ago. 2008.

VILLA, Marco A. Reforma agrária reduzida. São Paulo: Folha de São Paulo. 11 de fev. de 2001. Disponível em https://www1.folha.uol.com.br/fsp/mais/fs1102200114.htm. Acessado em 20 de out. de 2020 .

Submetido em: 29/10/2020

Aprovado em: 15/12/2020 